or flow parallel to the bedding leads to extension of form ellipses oblique to fold limbs. Pushing over a pack of cards can illustrate the same principle. Only in the special case of perfectly equal movement in opposite senses does the direction of laminar flow coincide with that of extension. The cleavages, as Williams agrees, develop in the directions of extension oblique to the bedding.

\author{
Geology Department, \\ UNIVERSITY OF OTTAWA, \\ OtTawa, Canada.
}

31st August, 1962.
W. K. FYSON.

\title{
THE EVOLUTION OF GRYPHAEA
}

SIR,-While it is reassuring that Philip (1962), in his new analysis of Gryphaea, confirms my belief that the ratio of the periphery (P) to the length of the right valve $(R)$ is an adequate measure of the tightness of coiling, the way he uses my measurements by treating their relationship as linear is open to serious objection. As he seems to betray a failure to appreciate the biological grounds which led me to use logarithms I shall have to be much more explicit than in my original paper.

When I made direct plots of $\mathbf{P}$ against $\mathbf{R}$ I did not find a simple linear relationship (text-figures 1 and 2). Considering firstly the best balanced sample in regard to size, from the gmuendense $(=$ reynesi $)$ Subzone of Glamorgan, it will be seen that a line drawn through the points up to an $R$ value of about $25 \mathrm{~mm}$. will miss most of the points for the larger specimens which fall on a slightly steeper curve. The beginning of a similar curvilinear upward trend is also seen in the upper angulata $(=$ complanata $)$ Subzone sample for the rest of England and there is no reason to believe that the remaining two samples exhibit different principles of growth. These graphs reflect what is clearly apparent on handling individual specimens, that the larger the size the tighter the coiling. These results suggested to me the possibility of a relationship of allometric type, which was confirmed when the logarithmic plots (text-figures 2 and 3 of my 1959 paper) were seen to conform much more closely to a straight line, indicating that the direct $P / R$ relationship is probably exponential.

Now the study of change in shape with size, far from being heretical, has become eminently orthodox in evolutionary studies (Simpson 1953, pp. 25-9) and the large body of work undertaken since the pioneer investigations of Huxley (1932) on allometric or relative growth make imperative a proper evaluation of this factor whenever the slightest suspicion exists of deviation from simple linear relationships of different measures. Yet Philip shows no evident appreciation of its importance. His key equation (v) assumes an equiangular spiral, which Gryphaea manifestly is not, since if it were $\mathbf{P}$ and $\mathbf{R}$ would plot as a straight line, and his treatment of variation only in adult shells becomes pointless. It is not surprising that his $P / R$ regression lines of the younger. larger forms show a highly significant increase in tightness of coiling compared with the older, but in the circumstances such results can have little meaning in terms of evolution.

Philip, of course, like Trueman, recognizes that tightness of coiling may increase during the life of at least some individuals but explains this as the consequence of selection for the more incurved forms. In proposing this explanation, he makes the statement that "the small individuals which died at an early age are usually loosely coiled and possess shell profiles not present in the initial portions of the adult specimens which survived to maturity ". The latter part of this statement does not accord with my own observations, nor is there a suggestion of anything but a continuum in the growth series at given horizons as plotted in text-figures 1 and 2 . 


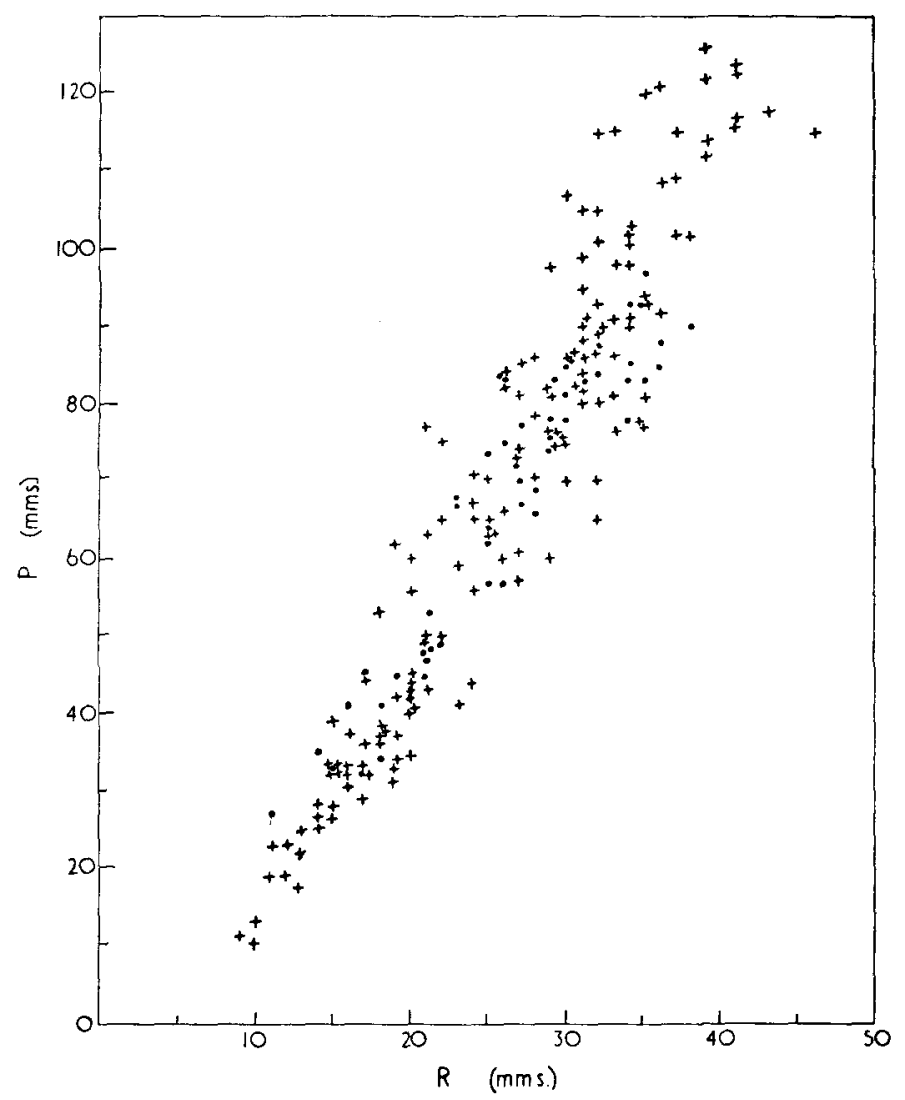

TEXT-FIG. 1.-Plots of periphery (P) against length of right value (R) for gryphaeas from Glamorgan. These results are presented separately because of the special interest of the type area and because Philip claims local peculiarities. Points represent specimens from the "angulata", crosses the "gmuendense" subzone.

The importance of all this concerns not merely the true character of the growth of Gryphaea but one of the essential bases of Trueman's hypothesis. The striking increase in tightness of coiling that he claimed in the Sinemurian, which may well have first suggested a relationship with the older Liostrea, must at least largely be spurious. An unprejudiced observer, looking at the graphs of samples from different horizons, could well be excused if he thought they represented a single growth series (compare the very different impression created by Fig. 1 of Trueman's 1922 paper). It is clear that any genuine evolutionary change must be far more subtle and could not possibly have been detected by the technique Trueman applied. This leads us on to the study of the logarithmic relationships.

Philip shows commendable zeal in obtaining the assistance of a computer to detect an apparent error in my first set of calculations. Assuming the machine is less fallible than the man, I would accept the possibility of a slight coiling change independent of ontogeny. This, however, does not disturb 


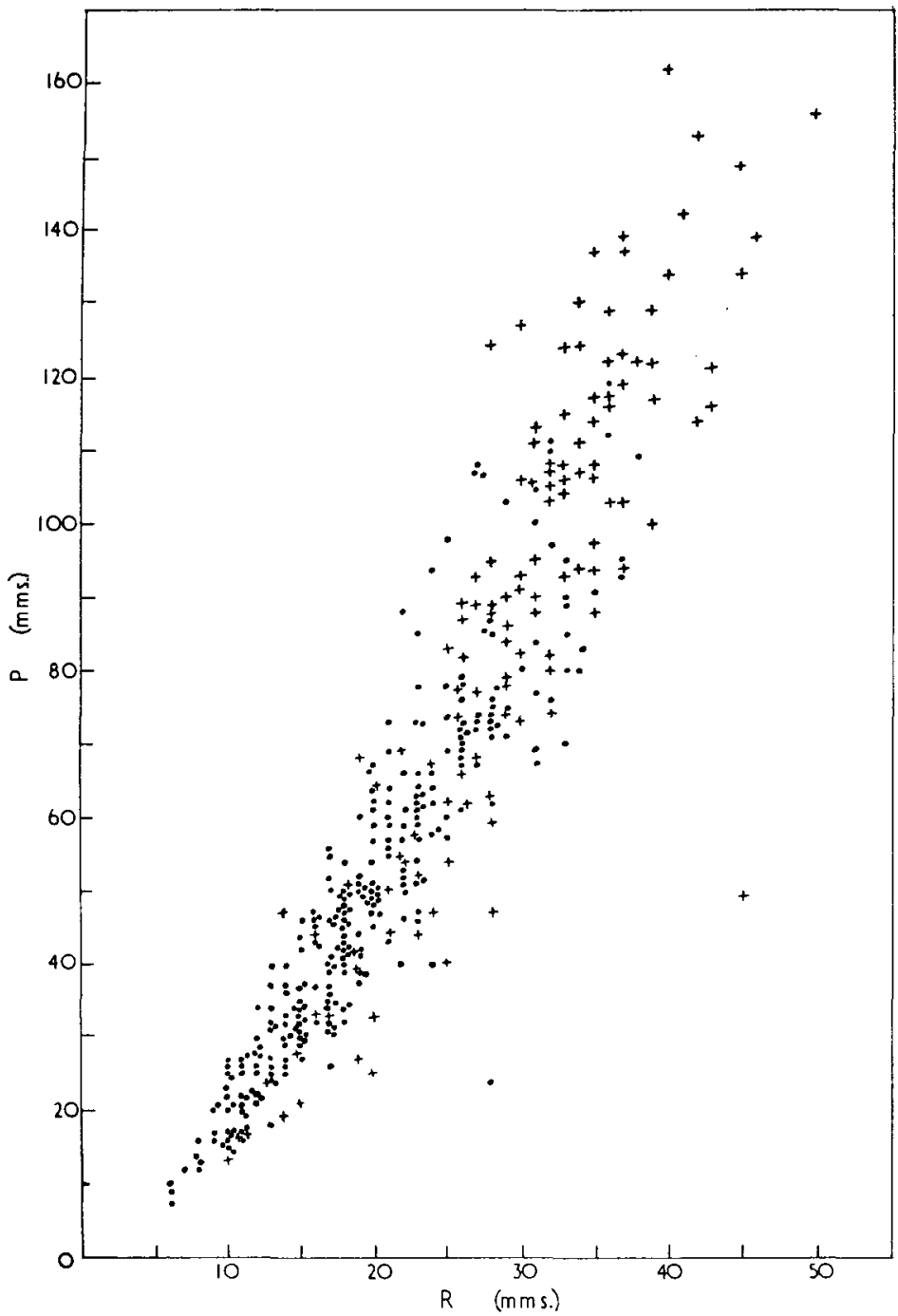

TeXT-FIG. 2.- Scatter diagram similar to text-figure 1 for gryphaeas from the rest of the country. Points represent specimens from the "angulata", crosses the bucklandi and "gmuendense" subzones. 
the crux of my argument, that there is no lineage embracing the Hettangian Liostrea and the Sinemurian Gryphaea. I have already accepted (1960) that the latter underwent an evolutionary increase in size, as with a number of other contemporary molluscs, and an additional change, which had nothing to do with the older oysters, can readily be accommodated within the framework of my interpretation.

To prove Trueman's hypothesis one must also demonstrate both an upward gryphaeoid trend in Liostrea and a gradual transition to Gryphaea at about the Hettangian-Sinemurian boundary. The latter is perhaps the more crucial and more easily checked in the field. It is illuminating in this regard to consider the situation in Glamorgan, where the most accessible locality for examination is in Stout Bay. Here, at the base of the succession, is a horizon rich in massive specimens of Liostrea (Sedg. Mus. J 48512 (1-13)) which reach an abnormally large size ( $\max$. length $70 \mathrm{~mm}$. max. breadth $63 \mathrm{~mm}$.). Following some 35 feet of virtually barren limestones and marls comes a horizon with abundant gryphaeas (J 48153 (1-44)), strikingly different from the liostreas in, among other things, the length/breadth ratio and in their appreciably smaller size (max. length of left valve $48 \mathrm{~mm}$., max. breadth $35 \mathrm{~mm}$.). No confusion whatever is possible between the vast majority of specimens from the two horizons. Philip's suggestion that the only change involved is a reduction in the size of the attachment area therefore receives no support in the type area. Nor is there any evidence from the rocks of the sudden change being related to an increase in muddiness (Maclennan and Trueman 1942). I should add that in the more condensed successions outside Glamorgan the sharp break between Liostrea and Gryphaea is seen within a much smaller thickness of rock, and that my subsequent field investigations have only sought to confirm my original claims.

Finally, Philip takes me to task for not supplying a convincing alternative explanation of the evolution of Gryphaea. I maintained a deliberate reticence on this subject as my essential concern was to challenge Trueman's views, but I can readily give at least two alternatives. Gryphaea could have migrated swiftly into the west European area, replacing Liostrea by ecological competition, following gradual evolution elsewhere or, what I regard as more probable, it evolved quite suddenly by the acquisition of some highly adaptive character which quickly enabled it to compete successfully with its predecessor. (If, as seems quite likely, the adaptive advantage related to the raising of the shell margin above a surface of soft mud, selection could well favour a slight increase in coiling up to a certain point of physical stability). This interpretation is more in accord with the experience of most invertebrate palaeontologists who, despite continued collecting all over the world and an ever increasing amount of research, find "cryptogenic" genera and species far more commonly than they detect gradual trends or lineages. The sort of evolution I tentatively propose for Gryphaea could in fact be quite normal among the invertebrates. Philip describes Trueman's original paper as one of the most outstanding contributions to British palaeontology. With respect, I think it may have been one of the most misleading.

\section{REFERENCES}

Hallam, A., 1960. A sedimentary and faunal study of the Blue Lias of Dorset and Glamorgan. Phil. Trans. roy. Soc. B, 243, $1-44$.

HuXLeY, J. S., 1932. Problems of relative growth. London.

Maclennan, R. M. and A. E. Trueman, 1942. Variation in Gryphaea incurva (Sow.) from the Lower Lias of Loch Aline, Argyll. Proc. roy. Soc. Edinb., B, 61, 211-233.

Philip, G. M., 1962. The Evolution of Gryphaea. Geol. Mag, 99, 327-344. Simpson, G. G., 1953. The major features of evolution. New York.

Grant lnstitute of Geology

a. Hallam.

UNIVERSITY OF EDINBURGH.

18th September, 1962. 